\title{
CURRÍCULOS INTERCULTURAIS PARA ESCOLAS INDIGENAS: NOVOS DESAFIOS
}

\author{
INTERCULTURAL CURRICULUM FOR INDIGENOUS SCHOOLS: NEW CHALLENGES \\ CURRÍCULOS INTERCULTURALES PARA ESCUELAS INDÍGENAS: NUEVOS RETOS
}

\author{
Darci Secchi* \\ ufmt.darci.secchi@gmail.com \\ Elen Luci Prates** \\ elencefaprocba@hotmail.com
}

\begin{abstract}
REVISTA PEDAGÓGICA
Revista do Programa de Pós-graduação em Educação da Unochapecó | ISSN 1984-1566

Universidade Comunitária da Região de Chapecó | Chapecó-SC, Brasil

Como referenciar este artigo: SECCHI, D.; PRATES, E. L. Currículos interculturais para escolas indígenas: novos desafios. Revista Pedagógica, Chapecó, v. 17, n. 34, p. 117-132, jan/abr. 2015.
\end{abstract}

\begin{abstract}
RESUMO: $O$ atual modelo de escolarização indígena teve sua origem associada à Convenção 107 da Organização Internacional do Trabalho (OIT) que procurou incorporar o chamado "Terceiro Mundo" ao projeto liberal. Tal estratégia caracterizou uma nova etapa da colonialidade e pretendeu solucionar o problema da diferença confinando-a em guetos, acampamentos, favelas e reservas indígenas. Naquele contexto, a escola tornou-se uma agência padronizadora de identidades e disponibilizadora de mão de obra. Passado mais de meio século, a escola indígena marcou presença nas florestas, nos cerrados e, mais recentemente, no meio suburbano brasileiro. Poderia, essa escola, nascida da colonialidade, transformar-se em uma instituição voltada para os interesses e as necessidades dessas populações? Entendemos que a adoção de um sistema próprio, organizado por etnoterritórios, poderá superar o atual quadro de apatia e alienação e trazer um novo alento para as sociedades ameríndias.
\end{abstract}

PALAVRAS-CHAVE: Escolas indígenas. Interculturalidade. Etnoterritórios. Colonialidade.

ABSTRACT: The current model of indigenous schooling had its origin associated with the 107 Convention of the International Labour Organization (ILO) which aimed to incorporate the so-called "Third World" to the liberal project. This strategy featured a new phase of colonialism and aimed to solve the problem of difference, confining it in ghettos, camps, slums and indigenous areas. In that context, school became an agency of identity standardization and provider of labor force. More than half a century later indigenous school was present in forests, savannahs, and, more recently, in Brazilian suburban area. Could this school, born from colonialism, become an institution focused on interests and needs of these populations? We understand that the adoption of a proper system organized by ethnic territories can overcome the current picture of apathy and alienation and bring new hope for Amerindian societies.

KEYWORDS: Indigenous schools. Interculturalism. Ethnic territories. Colonialism.

RESUMEN: El actual modelo de escolarización indígena tuvo su origen asociada a la Convención 107, de la Organización Internacional del Trabajo - OIT, que buscó incorporar el llamado "Tercer Mundo" al proyecto liberal. Tal estrategia caracterizó una nueva etapa de la colonialidad y pretendió solucionar el problema de la diferencia confinándola en guetos, acampamientos, favelas y reservas indígenas. En aquel contexto, la escuela se tornó una agencia que estandariza identidades y que dispone de mano de obra. Pasado más de medio siglo, la escuela indígena ya es una realidad en las florestas, en los campos y, más recientemente, en el medio suburbano brasileño. ¿Podría, esa escuela, nascida de la colonialidad, convertirse en una institución dedicada a los intereses y necesidades de estas poblaciones? Entendemos que la adopción de un sistema propio organizado por etnoterritorios podrá superar el actual cuadro de apatía y alienación y traer un nuevo aliento para las sociedades amerindias.

PALABRAS CLAVE: Escuelas indígenas. Interculturalidad. Etnoterritorios. Colonialidad. 


\begin{abstract}
* Professor Associado III da UFMT, doutor em Ciências Sociais (Antropologia) pela PUC/SP, membro do PPGE/IE e tutor do Grupo PET-Educação.

** Professora Formadora da SEDUC/MT, especialista em Arteterapia pela Faculdade de Cuiabá, cursando Mestrado em Educação pelo PPGE/IE/UFMT - Grupo de Pesquisa em Educação Escolar Indígena.
\end{abstract}

\section{APRESENTAÇÃO}

Para iniciar a apresentação da temática anunciada no título do presente artigo, pretendemos marcar posição quanto a uma noção que considero emblemática no campo da educação escolar indígena, por conter, a meu ver, uma redundância reveladora. Trata-se da expressão "escola intercultural", utilizada, via de regra, em oposição à denominada (e indesejada) "escola monocultural", pretensamente hegemônica no atual cenário indígena brasileiro.

Nosso argumento em desfavor dessa expressão, encaminha-se no sentido de que uma escola monocultural indígena não é uma realidade plausível. Então, se é uma escola indígena, deve conter os dois polos da expressão que a constitui: o de escola (que se caracteriza como uma instituição externa que vem sendo incorporada à realidade indígena), e o de indígena (dirigida aos estudantes das diferentes populações originárias). Porquanto, sempre que se tratar de escola indígena ela será, necessariamente, intercultural, uma vez que aporta os conhecimentos das sociedades que historicamente a instituíram, bem como os conhecimentos advindos das comunidades específicas (ou das sociedades) que passaram a incorporá-la.

A percepção de que possam existir escolas indígenas monoculturais funda-se em argumentos coloniais que, ao longo da história, invariavelmente, desconsideraram os saberes locais tanto na educação quanto nas demais relações estabelecidas com os "gentios". Em seu afã de eliminar a alteridade, a colonialidade ${ }^{1}$ e tornou invisíveis ou proibitivas as demais formas de perceber o mundo e de reproduzir a vida social e natural.

No campo da escolarização, o modelo colonial ignorou a identidade e a existência do ser indígena e preconizou a "ninguendade", a coisificação do outro (RIBEIRO, 2006). Mas, ainda assim, as culturas indígenas "emprenharam a escola" e impuseram a interculturalidade, não obstante o desejo adverso do colonizador. O modo de conceber a escola apenas como um "elemento cultural externo", desconsidera o inevitável convívio dos saberes. Ora, se na escola tem estudantes indígenas, nela haverá cultura indígena. $\mathrm{E}$, havendo cultura indígena, a escola não poderá ser monocultural, mas, sempre, intercultural. Ainda que indesejado ou impedido, o espaço escolar estará sempre prenhe de elementos culturais autóctones que convivem (ou são negados), pelos demais saberes. Porquanto, a expressão escola monocultural caracteriza uma abstração; e a escola indígena intercultural, uma redundância impregnada de colonialidade.

Outra discussão é aquela que trata dos conteúdos curriculares priorizados e disponibilizados pelas escolas indígenas. Nela cabe, obviamente, a preocupação com a presença e o predomínio desses ou daqueles saberes. Há de se perguntar: quais e quantum desses saberes incorporados ao currículo são externos (ou não são próprios)? Quais 
2 Para Clastres (19988) o dilema consistia em afirmar os índios "criaturas de Deus" e, ao mesmo tempo, promover a sua captura e escravização. A saída legal encontrada para burlar a interdição e promover guerras aos nativos se daria com a declaração (unilateral) da "prática antropofágica".

${ }^{3}$ A última missão jesuítica para índios em regime de funcionou até o ano de 1971. Estava instalada em Utiariti (uma antiga estação telegráfica de Rondon, no médio norte mato-grossense). Por suas escolas, passaram centenas de jovens e crianças de diversas etnias daquela região. Os padres salesianos ainda mantêm diversas missões religiosas para índios em Mato Grosso e em outros estados do Brasil. e quantum deles estão sendo apropriados (ou sendo impostos)? Quais as estratégias pedagógicas priorizadas (ou ignoradas)?

É esse o debate que perpassa o presente artigo e que se circunscreve em um contexto de reflexão acadêmica, bem como de elaboração e execução de políticas públicas convergentes com os interesses e as necessidades das sociedades indígenas atuais.

Pontuadas essas questões preliminares, é possível avançar para uma segunda constatação: a de que (quase) todas as sociedades indígenas latino-americanas atualmente convivem com algum tipo de escola. Umas a conheceram há quase quinhentos anos; outras, ao longo do processo de expansão capitalista e da sociedade moderna. Em todos os casos, a instituição escolar foi percebida apenas como um elemento externo às culturas indígenas e o seu conteúdo colonial predominou nas relações interculturais.

Se retornarmos ao passado dos "descobrimentos", perceberemos que os debates acerca da escolarização de indígenas tinham como cenário o confronto visual dos colonizadores com os habitantes das terras recém-conhecidas. Discutia-se o estatuto desses seres naturais e o lugar que lhes caberia no projeto de exploração. A questão que se colocava para a escola era declará-los humanos e, tendo alma, educá-los na fé cristã. A controvérsia ${ }^{2}$ acerca da natureza humana dos índios perdurou por dois séculos e, a partir dela, se estabeleceram os contornos da colonialidade em todos os países latino-americanos.

No Brasil, o ideário colonial ensinado nas missões e nas escolas religiosas predominou por quatro séculos e se manteve hegemônico, com algumas variações, até os nossos tempos ${ }^{3}$. Nas últimas décadas, porém, verificaram-se significativas mudanças no tratamento da temática educacional. Os próprios índios passaram a debater os programas de escolarização e a exigir uma escola voltada para os seus interesses e necessidades. A educação escolar tornou-se uma política pública; um direito de cidadania. A diversidade cultural foi aceita formalmente na legislação, assim como os direitos específicos e a liturgia diferenciada para as suas escolas. Tais avanços indicaram um porvir de cidadania, de respeito e de valorização das sociedades indígenas contemporâneas.

Hoje já não se discute se os índios têm ou não têm alma, se devem ou não ser "civilizados", mas se aceita que sejam declarados cidadãos com direitos específicos e diferenciados. A secular matriz colonial, entretanto, não foi totalmente superada. As atuais leis e os regulamentos foram produzidos apenas com a "audiência" dos índios, ou "contaram com a participação das comunidades". Ou, dito de outra forma: a legislação admitiu a alteridade e tolerou a diferença, mas se resguardou o direito de lhes conceder tais direitos. 
${ }^{4}$ Ribeiro (1970) e Oliveira (1995) utilizam as expressões "problema" ou "problemática indígena"; Silva (1987) e outros preferem "questão indígena”. Tomo-as aqui como sinônimos.
Segundo Brand (1998a), ao delimitar os assuntos indígenas ${ }^{4}$ aos cânones jurídicos, avançou-se apenas no arcabouço legal, esquecendo-se do verdadeiro "confinamento geográfico e social" ao qual os indígenas foram submetidos. Para o autor, essa estratégia de ação representa uma nova fase da colonialidade que pretende solucionar o problema das diferenças confinando-a em favelas, acampamentos e reservas. Como sua mão de obra já não é mais necessária ao projeto colonial, melhor integrá-los, isso é, torná-los invisíveis em um meio social marginal. E essa tarefa cabe especialmente à escola indígena, a nova instituição que se consolida, inexoravelmente, em todas as aldeias das florestas, dos campos e cerrados e, mais recentemente, também do meio suburbano brasileiro.

É dessa nova configuração das escolas indígenas, dos seus avanços e desafios, que trataremos especificamente nesse artigo.

\section{O DISCURSO OFICIAL SOBRE AS ESCOLAS INDÍGENAS}

O modelo integracionista de educação escolar para os índios está associado, no Brasil, ao binômio proselitismo doutrinário (religioso ou não) e à preparação para o trabalho. Com esses propósitos atuaram as missões católicas, as escolas pombalinas, a educação positivista e os missionários e linguistas de diferentes confissões evangélicas cristãs.

A partir da década de 1950, insuflados pelos ares da modernidade e das novas relações internacionais do trabalho, passaram a ser incorporados nos países do chamado "Terceiro Mundo" novos instrumentos jurídicos e novos objetivos para a educação escolar das "populações tribais e semitribais". A Convenção 107 da OIT (1957) preconizou, dentre outros direitos, a garantia de educação em todos os níveis (Art. 21); a realização de estudos antropológicos prévios à elaboração de programas escolares (Art. 22); a alfabetização em língua materna seguida de educação bilíngue (Art. 23); uma campanha de combate ao preconceito (Art. 25) e a divulgação dos direitos e obrigações sociais e trabalhistas por meio de informações escritas nas próprias línguas (Art. 26). Somente uma década mais tarde esses dispositivos ingressaram no mundo jurídico brasileiro e só se materializaram de fato na Constituição Federal de 1988. Mesmo assim, careciam de maiores explicitações, o que seria formalizado apenas em meados da década de 1990 com a publicação da Lei de Diretrizes e Bases da Educação Nacional (LDB) - Lei $n^{0}$ 9.394/96, de 20 de dezembro de 1996 (BRASIL, 1996).

Assim, é possível perceber que, nos últimos anos, os instrumentos jurídicos e administrativos concernentes à criação, à implementação e ao reconhecimento das escolas indígenas se multiplicaram e aperfeiçoaram. No entanto, as mudanças tiveram apenas um alcance formal e não 
5 Posteriormente, na Convenção 169, adotada pela $76^{\mathrm{a}}$ Conferência Internacional do Trabalho, em Genebra, em junho de 1989, foram revisadas essas proposições e acrescentadas outras diretrizes, tais como "[...] el derecho a la autoidentificación, a la consulta y a la participación, y el derecho a decidir sus proprias prioridades". significaram um rompimento conceitual com o modelo escolar anterior. A um observador atento, caberá perguntar se o atual paradigma da escola específica, diferenciada, bilíngue e intercultural, isso é, da escola adaptada formalmente à clientela, não é a antiga escola colonial, apenas ficando esta "fantasiada de novos adjetivos". E esse consenso virtual acerca de seus atributos não é, por si só, motivo de inquietação epistemológica? De onde partem tais formulações e quais as matrizes conceituais que as inspiram?

Certamente, o atual modelo de escola indígena teve a sua origem associada à Convenção 107 da OIT que redefiniu as relações internacionais do trabalho e ensejou incorporar as populações do "Terceiro Mundo" ao projeto liberal. Naquele contexto e sem nenhuma "maquiagem", propôs-se às escolas indígenas a função de agências padronizadoras de identidades e disponibilizadoras de mão de obra.

Vejamos como tais propósitos foram expressos:

Art. 24 - O ensino primário deverá ter por objetivo dar às crianças pertencentes às populações interessadas conhecimentos gerais e aptidões que as auxiliem a se integrar na comunidade nacional.

[...]

Art. 26 -1. Os governos deverão tomar medidas [...] com o objetivo de lhes fazer conhecer seus direitos e obrigações especialmente no que diz respeito ao trabalho e os serviços sociais. (ORGANIZAÇÃO INTERNACIONAL DO TRABALHO,1957, Grifos nossos) ${ }^{5}$.

Assim concebidos, os programas escolares (e as suas adaptações) foram formulados anterior e exteriormente à participação das sociedades indígenas, limitando-as apenas ao seu cumprimento.

Essa perspectiva encontra-se explícita também na atual LDB, em seu Art. 79, primeiro parágrafo, ao preconizar que: "Os seus programas serão planejados com a audiência das comunidades indígenas" (BRASIL, 1996, grifos nossos). Segundo a lei, as agências externas (governos, academias, conselhos) planejarão os programas das escolas, com a audiência indígena, e não o inverso: as comunidades indígenas planejarão seus programas com a audiência do poder público, dos conselhos e da academia.

A atual legislação reafirmou a sua origem colonial e deixou de contemplar uma premissa fundamental para a superação do modelo escolar integracionista, qual seja, a possibilidade de iniciativa das sociedades indígenas no processo de conceber, planejar, executar e gerir os seus currículos e programas educacionais. Resguardou o direito de outorgar direitos. Os índios permaneceram na qualidade de ouvintes e não de propositores de suas próprias políticas. Por força da lei, continuaram meros espectadores ou atores coadjuvantes, sem direito ao voto nem ao veto. 
${ }^{6}$ Silva (1999) comenta que uma análise crítica sobre a atuação do SIL pode ser encontrada também em Barros (1993) e em outros trabalhos da autora.
Um segundo aspecto problemático desse modelo escolar diz respeito à sua adjetivação enquanto "escola bilíngue". Em sua primeira formulação, denominada "bilinguismo de transição" propunha-se assegurar "[...] a transição progressiva da língua materna ou vernacular para a língua nacional ou para uma das línguas oficiais do país" (ORGANIZAÇÃO INTERNACIONAL DO TRABALHO, 1957, Art. 23, Inciso 2). Essa empreitada seria atribuída no Brasil aos missionários-linguistas do Summer Institute of Linguistics - SIL, mediante uma Portaria da FUNAI (75/72) que conferiu à agência norte-americana o status, o privilégio e o foro "oficial" no que tratasse de assuntos linguísticos para escolas indígenas. Segundo o antropólogo Silva (1999, p. 10), a parceria entre o Estado e o SIL foi tamanha "[...] que até mesmo as ferramentas analíticas desenvolvidas pelos linguistas do S. I. L. passaram a figurar dos documentos oficiais" 6 .

As críticas ao modelo do bilinguismo de transição não tardaram a se avolumar; afinal, tratava-se da mais "repulsiva forma de etnocídio" (SILVA, 1999, p. 10). Mesmo assim, perdurou por três décadas, até ser substituído na legislação escolar por sua abordagem antagônica, aqui denominada de bilinguismo compulsório. Se, antes, a educação escolar pretendia a substituição gradativa das línguas indígenas pelo português, agora, a situação se inverteria. $\mathrm{O}$ bilinguismo passou a ser uma característica inerente às escolas indígenas e seus estudantes deveriam ser, compulsoriamente, bilíngues.

O documento "Diretrizes para a Política Nacional de Educação Escolar Indígena" produzido pelo Comitê de Educação Escolar Indígena do MEC e lançado em 1994, não deixou dúvidas:

A escola indígena tem que ser parte do sistema de educação de cada povo, na qual, ao mesmo tempo em que assegura e fortalece a tradição e o modo de ser indígena, fortalecem-se os elementos para uma relação positiva com outras sociedades. [...] Como decorrência da visão exposta, a educação escolar indígena tem que ser_necessariamente específica e diferenciada, intercultural e bilíngüe (sic). (MEC, 1994a, p. 12, grifo nosso).

Parece óbvio que essa formulação generalista carece de sustentação, embora não se questione a adoção do bilinguismo em situações sociolinguísticas diglóssicas. O seu ponto crítico reside na formulação enquanto modelo tipológico obrigatório e único para as escolas indígenas. Poderíamos perguntar, por exemplo, como se daria o ensino bilíngue em escolas indígenas cujos alunos são monolíngues em português? Ou inversamente, como seria a escolha de apenas duas línguas em situações de multilinguismo? Essas realidades, brilhantemente debatidas por Silva (1994, p. 13) longe serem "meras exceções", correspondem 
7 O autor destaca que há na Amazônia o multilinguismo no alto rio Negro. E, como monolíngues em português, cita diversas comunidades do médio Solimões e baixo rio Madeira. O mesmo ocorre com diversas sociedades indígenas do Nordeste brasileiro. a uma expressiva parcela da população indígena brasileira. São inúmeros os casos em que "[...] coexistem, em um mesmo contexto, mais de uma língua indígena e os casos em que a 'língua indígena' é a própria língua nacional”7. Portanto, a escola verdadeiramente indígena não é necessariamente bilíngue, embora o bilinguismo possa ser atualmente recorrente em muitas escolas.

Mais do que uma adjetivação obrigatória para as escolas indígenas, o ensino bilíngue deveria constituir-se em uma opção das comunidades, e como tal, poderia compor ou não o currículo e o cotidiano de suas escolas. Essa escolha, porém, mais uma vez foi subtraída das comunidades e impingida como um direito estabelecido pela legislação. Mais uma vez, admitiu-se a diversidade e domesticou-se a diferença; contudo abrir mão do direito de conceder direitos.

O mesmo vício colonial ocorre com os dois adjetivos restantes: as escolas indígenas devem ser específicas e diferenciadas. Esses direitos compulsórios anunciados e cultuados como "novos avanços", ratificam a perspectiva discriminatória e de desqualificação das minorias étnicas e culturais. As escolas indígenas (como também as escolas rurais, ribeirinhas e das favelas) devem ser específicas e diferenciadas para "reproduzirem os conhecimentos próprios", isso é, para reproduzirem a negação cultural, a negação identitária e a negação da cidadania, elementos que compõem a essência do cotidiano de quem se sabe e se reconhece historicamente discriminado.

Talvez resida aí a dificuldade de os professores e lideranças indígenas perceberem os currículos diferenciados como algo positivo para as suas escolas. "Até agora só sabemos o que é diferenciado para pior e nunca para melhor" alertava, já em 2001, o presidente da Associação Terra Indígena do Xingu - ATIX, Marawê Kayabi, ao debater a regularização das escolas xinguanas. Como se percebe, uma política de reconhecimento de direitos também pode ser etnocêntrica ou alienante na medida em que os define e os expressa em sua própria gramática.

\section{REPENSANDO O CURRÍCULO DAS ESCOLAS INDÍGENAS}

A atual concepção hegemônica acerca das escolas indígenas resume-se, como vimos, aos quatro adjetivos comentados (específica, diferenciada, bilíngue e intercultural), e a uma atitude valorativa de respeito à diversidade e aos processos pedagógicos próprios. É preciso, portanto, substantivar essa versão conjuntiva de escola indígena com ingredientes que espelhem a pluralidade das situações escolares atualmente existentes.

Uma excelente contribuição nesse sentido foi apresentada pelo historiador Brand (1998a, p. 7), para quem as escolas indígenas devem atender a dois desafios principais:

a) ser um instrumento de afirmação étnica e de coesão interna a serviço dos projetos de autonomia de cada povo ou comunidade; 
b) capacitar individual e coletivamente cada pessoa, comunidade e povo indígena para o enfrentamento e a ocupação dos espaços de participação em âmbito regional e nacional.

Um entendimento similar pode sem encontrado também em Maher (1996), Melià (1997 e 1998) e Silva (1997) que caracterizam as escolas indígenas com os seguintes atributos:

a) nova instituição educacional, a serviço de cada povo;

b) instrumento de afirmação e reelaboração cultural;

c) elemento que contribui na conquista de espaço político;

d) alternativa aos modelos anteriores de "escolas para os índios";

e) lugar onde se articulam os conhecimentos tradicionais e os novos conhecimentos;

f) espaço em que se disponibilizam informações decorrentes do contato;

g) possibilidade de construção de relações igualitárias, do reconhecimento e do respeito individual e social;

h) espaço de construção da contraideologia.

Para Ferreira (1992) cada povo desenvolve alternativas de ação e implementa dinâmicas próprias para fazer frente a essa situação de contato. A escola aparece como um dos instrumentos a serem acionados, ora como espaço de construção de identidades étnicas, ora como instância de interlocução com a sociedade não índia. Para a autora, são os índios que têm o "[...] direito de definir as próprias concepções de educação escolar, de acordo com os processos tradicionais de aprendizagem e os interesses de cada sociedade" (FERREIRA, 1992, p. 179).

É nessa direção que se encaminham também as proposições dos professores indígenas ao definirem as principais competências dos currículos escolares. Para eles, o currículo das escolas indígenas deve expressar as práticas sociais e culturais de cada comunidade e disponibilizar os conhecimentos autóctones e das ciências, de modo que possam ser utilizados adequadamente em cada realidade concreta.

No entanto, ainda existe um hiato preocupante entre o que é pensado (idealizado) nos cursos de formação e o que é vivido (realizado) nas escolas das comunidades. Nas palavras de um acadêmico do Curso de Licenciatura Indígena: "Imaginamos um tipo de escola, mas fazer na realidade o que se aprende não é fácil. Só alguns conseguem" (SECCHI, 2005, p. 26). De fato, conjugar a racionalidade científica ocidental com as dos sistemas de saberes indígenas não é tarefa fácil. Somam-se a ela outros aspectos intracurriculares como as ênfases teóricas e metodológicas, os recortes das áreas, a lógica dos conteúdos, a organização disciplinar, as estratégias de avaliação etc. e teremos uma pequena amostra da complexidade e do desafio que envolve a composição dos currículos das escolas indígenas. 
${ }^{8}$ Além das instituições proponentes, participaram professores e diretores das escolas indígenas de todo o estado, representantes da Universidade Federal de Mato Grosso, Universidade do Estado de Mato Grosso, Fundação Nacional do Índio, Secretarias Municipais de Educação e de organizações não governamentais.

${ }^{9}$ Além das instituições proponentes, participaram professores e diretores das escolas indígenas de todo o estado, representantes da Universidade Federal de Mato Grosso, Universidade do Estado de Mato Grosso, Fundação Nacional do Índio, Secretarias Municipais de Educação e de organizações não governamentais.
É nesse misto de angústia e incertezas que os professores indígenas e as agências formadoras (Universidades, Secretarias etc.) se sentem como "aprendizes de feiticeiros" em busca de caminhos para a produção de currículos convergentes com os interesses e as necessidades indígenas. De outra parte, é compreensível que alguns se dizem "contemplados" quando recebem, já impressos, os "subsídios oficiais" na forma de diretrizes, parâmetros ou referenciais que balizam (norteiam) as atividades docentes.

Esse dilema, aparentemente insolúvel, de gerar currículos específicos e, ao mesmo tempo, assegurar o "marco nacional", foi encaminhado de forma inovadora, recentemente, em Mato Grosso. Por se tratar de uma iniciativa inédita e que poderá ensejar replicações em outras regiões, apresentarei a seguir uma breve síntese dos seus principais contornos.

A iniciativa denominada "Construção coletiva de orientações curriculares" foi desenvolvida no estado entre os anos de 2009 e 2012 e teve caráter interinstitucional e intercultural. Os trabalhos foram organizados pelo Conselho de Educação Escolar Indígena e pela Secretaria de Estado de Educação e contaram com a participação de representantes das comunidades e das instituições que atuam com essa temática educacional ${ }^{8}$.

Para assegurar que as proposições geradas nos diferentes âmbitos fossem apreciadas, adotou-se uma dinâmica em que as comunidades discutiam seus projetos nas comunidades, em seguida, participavam de reuniões nos polos regionais e, finalmente, sistematizavam as diversas proposições na forma de um documento geral de âmbito estadual. Com essa estratégia, cada escola pode produzir coletivamente o seu projeto e contribuir para a formulação das orientações curriculares para as demais escolas.

Como forma de suscitar a reflexão e instigar a participação, foi formulada a seguinte questão, considerada fundamental o currículo das escolas indígenas: "Que escola indígena precisamos para fortalecer a nossa cultura, dominar novos conhecimentos, ampliar a nossa autonomia e sermos construtores de uma sociedade mais justa, saudável e feliz?” (SEDUC, 2010, p. 251).

As contribuições obtidas nos três âmbitos de elaboração (escolas, polos regionais e estado) foram organizadas por eixos temáticos ${ }^{9}$, de modo a facilitar a aproximação dos conteúdos e a articulação entre as áreas de formação (Linguagens, Ciências Humanas, Ciências Naturais e Matemática). Essa estratégia se mostrou adequada, também, como mediação intercultural ao destacar nos currículos os conhecimentos tradicionais de cada povo e os saberes advindos das relações com outros povos e com a sociedade moderna. A proposição de currículos escolares, mediados pelo diálogo intercultural e interinstitucional tornou-se uma opção política e metodológica eficaz pela oportunidade de aprendizado tanto para as instituições quanto para as comunidades. 
Dada à riqueza e peculiaridade das proposições colhidas nesse processo, reproduziremos, a seguir, alguns dos eixos temáticos e respectivos enunciados, elaborados coletivamente pelos participantes dos eventos. Vários deles passaram a ser utilizados como orientações curriculares nas escolas indígenas das redes municipais e estadual de Mato Grosso:

\section{a) Diversidade Étnica e Cultural}

Atualmente vivem em território mato-grossense dezenas de sociedades indígenas e muitos outros grupos e pessoas oriundas de diversos estados e países. A escola indígena precisa saber lidar com tamanha diversidade cultural na sala de aula e fora dela. Para tanto, deve respeitar e valorizar as características étnicas e culturais dessas populações; deve trabalhar com temas como o conhecimento da história, língua, direitos e expectativa de cada povo; deve lutar contra o preconceito, a discriminação, a opressão e a intolerância e promover a solidariedade entre os povos. Além disso, deve estar intimamente vinculada a todas as formas de expressão cultural da comunidade, como a língua, os rituais e as artes (música, pintura, dança etc.), dentre outras.

\section{b) Planeta Terra, Ambiente e Biodiversidade}

O Planeta, o seu ambiente e a sua biodiversidade são patrimônios fundamentais das sociedades humanas, portanto merecem todos os nossos cuidados. A Mãe Terra deve ser respeitada em todos os seus aspectos e potencialidades (físicos, biológicos, ambientais etc.) de maneira que a interação entre os seres humanos e a natureza seja sustentada e duradoura. A atual "crise ambiental" deve ser interpretada pela escola indígena como um exemplo impróprio de lidar com os recursos naturais e ambientais, como as prioridades econômicas e com os valores das sociedades modernas. O currículo das escolas deve contemplar essa temática em seus aspectos locais (como a sua comunidade lida com a terra, com o ambiente e com a biodiversidade) e em seus aspectos mais amplos, verificando o modelo de ocupação e desenvolvimento regional, nacional e mundial.

\section{c) Terras Indígenas, Organizações e Direitos In- dígenas}

Os direitos humanos em geral e os direitos indígenas em particular são temas fundamentais dos currículos escolares. O direito à vida, à terra e aos modos próprios de organização e representação são previstos na Constituição Federal e são adotados pelas sociedades 
indígenas como estratégias de manutenção cultural e da sua autodeterminação. No momento em que toda a sociedade retoma o debate acerca dos direitos indígenas, as escolas não podem deixar de discutir as especificidades das políticas públicas, a demarcação, o uso e a conservação das terras indígenas e as suas formas de organização e de representação, por se tratarem de temas fundamentais para a construção de sua da autonomia, liberdade e cidadania.

\section{d) Segurança Alimentar, Trabalho e Autossus- tentação}

A escola indígena não pode desconsiderar a situação de carência em que vive uma significativa parcela da população indígena de Mato Grosso. Para obter o autossustento com dignidade os povos indígenas atualmente necessitam de diferentes fontes de renda tais como os projetos de desenvolvimento coletivos e as alternativas individuais de trabalho remunerado. A escola pode contribuir para criar alternativas de trabalho, emprego, renda, utilização sustentada da terra e dos recursos naturais, agregação de valor em produtos naturais e artesanais, comerciais, manipulação de valores, gestão política, econômica e financeira, dentre outras. Para tanto, cada comunidade verificará as suas necessidades específicas e dirigirá as ações curriculares no sentido de supri-las e ou de buscar alternativas para o seu equacionamento.

\section{e) Educação para a Saúde}

A saúde indígena também tem sido um tema de preocupação tanto das comunidades quanto do poder público. Ao destacar esse eixo tático, pretende-se que as escolas e os órgãos de atendimento à saúde discutam os ensinamentos tradicionais, as atitudes, os comportamentos e as práticas pessoais e coletivas relativas à saúde e que possam compartilhar esses conhecimentos com toda a comunidade. Não se trata de enfocar apenas as doenças, suas causas e consequências, mas de educar para que todos possam ter uma vida saudável sem violência, stress e outros males que atingem as sociedades contemporâneas. Os assuntos relacionados à sexualidade, a DSTs e ao alcoolismo têm sido sempre objetos de grande preocupação nas comunidades indígenas de Mato Grosso.

\section{f) Ética, Justiça, Solidariedade e Paz}

Esse eixo temático trata da conduta que as pessoas e as sociedades devem desenvolver para que tenhamos uma vida digna e feliz. 
A escola deve construir a cultura da paz, da justiça e da igualdade entre todas as pessoas, povos e nações. As sociedades indígenas são reconhecidas pela generosidade, hospitalidade, respeito às coisas sagradas, aos mortos e à natureza. A escola pode contribuir para consolidar essa conduta e confirmar a opinião de que podemos viver numa sociedade unida e fortalecida por laços de solidariedade e respeito mútuo. (SEDUC, 2010, p. 251-253).

Como se percebe, as proposições citadas expressam os modos próprios das sociedades indígenas perceberem o mundo e suas relações sociais e com a escola, sem deixar de tratar dos temas advindos das relações interculturais, especialmente daqueles que afetam diretamente os seus modos de vida e de subsistência.

Para cada um dos temas geradores relacionados nos currículos escolares, foi associado um inventário de assuntos (ou conteúdos) que poderão ser tratados pelos docentes em cada área de conhecimento nos diferentes ciclos de formação. Os conteúdos curriculares são apresentados e debatidos em um espiral de complexidade crescente e perpassam todo o currículo escolar, desde os ciclos iniciais até o final do ensino básico.

Um movimento similar ocorre também em relação às áreas de conhecimento, uma vez que o recorte temático facilita a articulação entre os saberes e desconstrói os limites disciplinares. Por exemplo: no eixo temático denominado "Segurança alimentar, trabalho e autossustentação, ao tratar de temas como degradação dos solos, monocultura, desmatamento, grandes projetos agropecuários, estradas em terras indígenas, exploração madeireira e mineral etc.”, o currículo escolar trata, a um só tempo, do local e do geral; do disciplinar e do multidisciplinar; do cultural e do intercultural. A mesma dinâmica ocorre nos demais eixos e respectivos conteúdos curriculares.

Neste artigo, são será possível apresentar diversos aspectos que explicitariam mais amplamente os contornos daquele projeto. No entanto, o seu principal mérito está no fato de as proposições terem sido geradas nas escolas indígenas e, depois de percorrerem diversas instâncias de debate e aperfeiçoamento, terem retornado às escolas para serem utilizadas pelas equipes técnicas e por mais de uma centena de professores indígenas. $\mathrm{O}$ "produto final”, portanto, não se resumiu apenas a um fascículo impresso com orientações curriculares. $\mathrm{O}$ aprendizado mais significativo foi a práxis da construção coletiva pela qual todos puderam debater e confrontar suas prioridades, incorporar novos conteúdos e metodologias, enfim, estabelecer os contornos do seu Projeto Político Pedagógico.

Obviamente, não se tratou de uma panaceia ante aos desafios de gerar currículos e aplicá-los à realidade de cada povo. Tem-se presente que as escolas indígenas convivem com situações históricas que dificultam, quando não, 
impedem, a plena realização curricular. As mais lembradas dizem respeito à precariedade das instalações físicas e à falta de merenda, transporte, material didático, acompanhamento pedagógico, formação continuada, remuneração digna etc. No entanto, elas estão sendo fustigadas, também, por outros fatores cujo alcance pode fragilizá-las ainda mais. Destaco apenas dois: um de ordem interna e outro de amplitude mais abrangente.

$\mathrm{O}$ primeiro fator diz respeito à atuação dos próprios professores - especialmente daqueles formados nos cursos superiores indígenas -, quando no seu exercício docente não atendem adequadamente aos anseios comunitários, às exigências legais e aos princípios da sua formação. Sem um envolvimento efetivo, que não expressa uma profissionalidade, instaura-se nas escolas um pacto de precariedades (ou de mediocridade, se preferirem). Este pacto amplia as dificuldades evocadas, descompromete o poder público e enseja a apatia das respectivas comunidades educativas. Se considerarmos que, em muitas aldeias, os professores são a "personificação" de suas escolas, podemos sugerir que, sem o empenho destes, não haverá currículo escolar que frutifique.

O segundo fator limitante refere-se ao progressivo desequilíbrio na correlação de forças entre as sociedades indígenas, o entorno regional e o estado nacional. As políticas anti-indígenas que vicejam atualmente no Brasil se espraiam desde os matreiros palácios brasilienses aos mais bucólicos confins da Amazônia e afetam, diretamente, a centenas de povos e comunidades. Sem a restauração dos direitos indígenas, especialmente aqueles relacionados à demarcação e à segurança dos seus territórios, as escolas serão sempre acometidas do embotamento próprio dos tempos de angústia. Tempos adversos... Mais do que os de outrora!

\section{OLHANDO PARA O FUTURO}

Como já mencionamos, a escola indígena não é apenas um elemento cultural externo que vem sendo incorporado no cotidiano dessas sociedades. Esse ideário escolar - nascido da colonialidade - vem sendo disseminado, nas últimas décadas, por meio de diretrizes, referenciais, parâmetros, resoluções, pareceres etc. que pretendem o seu disciplinamento e padronização.

As conquistas legais e os avanços das políticas públicas verificados nas últimas décadas precisam ser ampliados, especialmente no que trata da sua efetiva realização no "chão da escola". Ou, como diria o poeta Drummond: as leis nãos bastam; os lírios não nascem das leis!

Uma vez universalizada a oferta da educação básica, o desafio que se coloca para o futuro já não é o da consolidação do modelo oficial, mas o da sua desconstrução. Por sabermos que "nenhuma sociedade que tenha conhecido a escola conseguiu desvencilhar-se dela", é importante que a reconfiguremos e a edifiquemos sobre novas bases. 
Dentre os desafios que se impõem, destacarei apenas dois, que considero relevantes para avançar no debate e na construção de escolas indígenas voltadas para os seus interesses e necessidades.

O primeiro desafio trata da desconstrução da modalidade de "escola indígena" atualmente hegemônico, quer no campo das representações, quer da sua apresentação formal. Há de se criar mecanismos que impeçam esse verdadeiro assédio oficial no sentido de padronizar as condutas escolares, por meio de formulários, registros e outros procedimentos formais que embaçam o foco essencial do trabalho docente. Tais artifícios, não raramente burlados ou dissimulados, pouco somam para construir o protagonismo indígena. Ao contrário, tornam-se meras precauções legais de alcance ético e pedagógico duvidosos. Ao instituir formalmente um sistema padronizado de procedimentos administrativos, financeiros e pedagógicos sem a participação indígena na sua concepção e sem um acompanhamento de percurso, o estado deseduca, induz ao erro, corrompe seus próprios fins. Esse quadro não pode ser superado pela outorga de responsabilidades (tão própria do modelo colonial), mas por sua desconstrução, isto é, pela ação autônoma e protagonista das comunidades educativas. Resumindo: o poder público municipal e estadual precisa superar, urgentemente, esse pseudomodelo de gestão pautado em listagens, planilhas, fichas, mapas, protocolos, ofícios, quadros, enfim, essa excrescência da colonialidade, e estabelecer linhas de comunicação e acompanhamento mais efetivas e dialógicas. De outra parte, as comunidades educativas indígenas também precisam driblar os subterfúgios a que se submetem e assumir o ônus e o bônus do seu protagonismo e da sua autonomia. Esse movimento nos dois polos da relação é urgente e indispensável para um advir de novas conquistas.

O segundo flanco a ser fustigado trata da reorganização conceitual e administrativa da atual "modalidade" de educação escolar indígena. Conceitualmente, porque o atual modelo oficial não está amplamente apoiado na realidade específica dos povos, vale dizer, nas suas culturas. Elementos culturais autóctones como parentesco, língua, economia e todos os demais marcadores de pertencimento ou de identidade são ofuscados pelas noções como as de interculturalidade, institucionalidade, marco nacional, calendário oficial e tantas outras medidas impostas pelo poder público. Administrativamente, porque as formas atuais de vinculação das escolas indígenas não atendem, nem precariamente, às demandas concretas. A realidade cultural e demográfica, especialmente com os países limítrofes, já não permite que continuemos a adotar políticas públicas nascidas da colonialidade, que nutrem o apartheid fronteiriço e que segmentam dezenas de povos ao longo da fronteira sul, oeste e norte do país. O mesmo desenho se reproduz, também, entre as unidades federadas (estados) e entre os municípios, cujos critérios de atendimento escolar 
referem-se apenas à localização física das aldeias ou moradias indígenas. Há de se pensar em um sistema próprio, com organização especial, que considere outros indicadores como os de parentesco, língua, economia, demografia e territorialidade.

Em suma, o debate em torno dos etnoterritórios educacionais indígenas precisa ser aprimorado e aprofundado de modo a se tornar, cada vez mais, um instrumento para a frutificação do protagonismo indígena.

\section{REFERÊNCIAS}

BRAND, A. O impacto da perda da terra sobre a tradição Kaiowá/Guarani: os difíceis caminhos da Palavra. 1998. Tese (Doutorado em História) - Programa de Pós-Graduação em História, Pontifícia Universidade Católica, Porto Alegre: PUC/RS, 1998a.

Autonomia e globalização, temas fundamentais no debate sobre Educação Escolar Indígena no contexto do Mercosul. In: ENCONTRO DE EDUCAÇÃO ESCOLAR INDÍGENA DA AMÉRICA LATINA, p. 07-20, Dourados, 1998b.

BRASIL. Lei no 9.394, de 20 de dezembro de 1996. Estabelece as diretrizes e bases da educação nacional. Diário Oficial da União, Brasília, DF, 23 dez. 1996. Disponível em: <http://www.planalto.gov.br/CCIVIL_03/leis/ L9394.htm>. Acesso em: 12/03/2015.

CEI/MT, Conselho de Educação Escolar Indígena do Estado de Mato Grosso. Urucum jenipapo e giz: a educação escolar indígena em debate. Cuiabá: SEDUC, 1997.

CLASTRES, P. Sociedade contra o estado. Pesquisas de antropologia política. Rio de Janeiro: Francisco Alves, 1988.

FERREIRA, M. Escrita e oralidade no Parque Indígena do Xingu. Inserção na vida social e a percepção dos índios. Revista de Antropologia, São Paulo, v. 35, p. 91-112, 1992.

MAHER, T. de J. M. Ser professor sendo índio: questões da língua(gem) e identidade. 1996. Tese (Doutorado em Linguística) - Programa de Pós-Graduação em Linguística, Instituto de Estudos da Linguagem, Universidade Estadual de Campinas, Campinas, 1996. Disponível em: <http://www.bibliotecadigital.unicamp.br/ document/?code=vtlsooo110213 $>$. Acesso em: 11/03/2015.

MEC. Diretrizes para a política nacional de educação escolar indígena/ Elaborado pelo comitê de Educação Escolar Indígena. Cadernos de Educação Básica. Série Institucional. 2. ed. Brasília: MEC/ SEF/DPEF, 1994a. 
Plano decenal de educação para todos 1993-2003. Brasília: MEC, 1994b.

MELIÀ B. El Paraguay inventado. Asunción del Paraguay: Centro de Estudios Paraguayos “AntonioGuasch”, 1997.

MELIÀ, B. Gua'i Rataypy: fragmentos del folklore Guaireño. Asunción: Fundación “León Cadogan”,1998.

ORGANIZAÇÃO INTERNACIONAL DO TRABALHO. Convenção no 107. 5 jun. 1957. Genebra: OIT, 1957. Disponível em: <http://www.oas.org/ $\mathrm{dil} /$ port/1957\% 2oConven\%C3\%A7\%C3\%A30\% 20 sobre\%2oPovos\%2oInd\%C3\%ADgenas\%20e\%20Tribais.\%20(Conven\%C3\%A7\%C3\%A30\%20OIT\%20n\%20 \%C2\%BA\%20107).pdf >. Acesso em: 14/03/2015.

Pueblos indígenas y tribales: guía para la aplicación del convenio 169 de la OIT. Genebra: OIT, 1996.

RIBEIRO, D. O povo brasileiro. São Paulo: Fundação Darcy Ribeiro, 2006.

SECCHI, D. Relatório da $2^{\mathbf{a}}$ avaliação externa do Terceiro Grau Indígena. Barra do Bugres: UNEMAT, 2005.

SEDUC. A construção coletiva de uma política de educação escolar indígena para Mato Grosso (versão preliminar). Cuiabá: SEDUC/CAIEMT/CEI/MT, 2001.

Orientações curriculares das diversidades educacionais. Cuiabá: SEDUC, 2010.

SILVA, J. F. da. "Utiariti - a última tarefa". In: WRIGHT, R. (Org.). Transformando os deuses. Os múltiplos sentidos da conversão entre os povos indígenas no Brasil. Campinas: Editora da Unicamp, 1999.

SILVA, M. A conquista da escola. Educação escolar e movimento de professores indígenas no Brasil. Em Aberto - MEC/INEP, Brasília, ano 14, n. 63, jul./set. 1994. Disponível em: <http://www.emaberto.inep.gov.br/index. php/emaberto/article/viewFile/944/849>. Acesso em: 15/03/2015.

SILVA, Rosa Helena Dias da. A autonomia como valor e a articulação de possibilidades: um estudo do movimento dos professores indígenas do Amazonas, Roraima e Acre, a partir dos seus encontros anuais. 1997. Tese (Doutorado em Educação) - Programa de Pós-Graduação em Educação, Universidade de São Paulo, São Paulo: USP, 1997.

UNEMAT. $3^{\mathbf{o}}$ grau indígena: projeto de formação de professores indígenas. Barra do Bugres: Universidade do Estado de Mato Grosso, 2002. 